\title{
SOBRE A PELEJA DOS SUJEITOS DA REFORMA, OU DA REFORMA DOS SUJEITOS EM PELEJA
}

\author{
Gastão Wagner de Sousa Campos *
}

O presente trabalho analisa os principais impasses da reforma sanitária brasileira, bem como avalia a atuação do movimento de saúde a nível das instituições. Aplicando à saúde conceitos de Gramsci, F. Guattari e Castoriadis, com o objetivo de identificar os processos de construção da subjetividade dos trabalhadores de saúde, propõe-se caminhos para a reforma dos sujeitos sociais nas práticas de saúde e como atores de um processo político de reforma.

Eu diria que o Movimento Sanitário brasileiro, nestas "noites" de hoje em dia, está padecendo de insônia em um "berço esplêndido". Seria injusto considerar que estaríamos "dormindo em berço esplêndido" tal é o grau de angústia, inquietação e desesperança entre aqueles que ainda esperam colocar as Instituições de Saúde a serviço da VIDA. Daí, a metáfora da insônia.

Sem dúvida, o "magnífico berço" seria o conjunto de diretrizes ordenadoras do Sistema Único de Saúde (SUS) expresso no texto da Constituição Federal de 1988: o direito à saúde, o dever do Estado em provê-la, a democratização da gestão, a organização segundo as idéias da descentralização, regionalização, hierarquização e integralidade do cuidado. Estrutura jurídico-legal construída depois

* Docente do Departamento de Medicina Preventiva e Social da UNICAMP. 
de muita peleja politica e criatividade técnica.

De qualquer maneira, acumulam-se evidências quanto à insuficiência de toda esta labuta, já que não se conseguiu derrotar o autoritarismo, a ineficácia e o clientelismo característicos do sistema público de saúde.

Inegavelmente, o predomínio de politicas estatais com os mais variados matizes de um neoliberalismo tacanho explica muito desta situação. Contudo, esta constatação não responde a uma série de questões que martelam a consciência de todos aqueles abertos às mensagens que a realidade nos transmite: por que não conseguimos, depois de mais de dez anos de regime democrático, superar estas polfticas restritivas e regressivas dos últimos governos no Brasil?

Ou seja, por que não fomos ainda capazes de constituir ATORES SOCIAIS com vontade e potência suficientes para reverter o quadro sanitário nacional?

Por que amplos setores da sociedade civil quase que só conseguem expressar suas necessidades em saúde por meio de um tormentoso movimento de milhões de indivíduos que somente demandam assistência? A agonia dos que batem à porta dos Centros de Saúde, Hospitais e Pronto-socorros e nem sempre encontram acolhida.

Por que as entidades sindicais, mesmo as mais organizadas e politizadas, apesar de todas as declarações de apreço ao SUS, aspiram, no seu cotidiano, à inclusão de seus filiados em alguma das modalidades da medicina de mercado?

Por que, via de regra, os movimentos de trabalhadores de saúde mantém-se ou apáticos e frustrados, ou aderem a lutas onde o imediatismo 
corporativo só é comparável ao seu ressentimento e a uma espécie de mágoa sem causa precisa?

Por que, apesar das boas intenções, a maioria dos governos populares democráticos ou progressistas, não puderam alterar as relações dos usuários e dos trabalhadores com as Instituições Públicas, criando novos padrões de expectativas e novos projetos?

Por que inúmeros participantes do Movimento Sanitário sentem-se tão desamparados sempre que não há um governo onde depositar esperanças e ao qual se delega a prerrogativa de tomar iniciativas?

É evidente que não conseguirei, no espaço deste artigo, responder a todas estas questões, mesmo porque algumas delas têm raízes em determinações históricas mais gerais. No entanto, gostaria de indicar algumas categorias que, ou por serem novas ou por estarem em desuso, têm sido pouco consideradas pela teoria e prática do Movimento de Reforma Sanitária.

A primeira refere-se ao processo de CONSTITUIÇÃO DE ATORES SOCIAIS capazes de alterar a correlação de forças, viabilizando transformações concretas no Sistema Público de Saúde.

Julgo que não temos dado a importância devida aos PROCESSOS DE PRODUÇÃO DE SUJEITOS SOCIAIS dotados de uma dada vontade política e de um projeto de reformas. Em realidade, a maior parte do esforço do Movimento Sanitário tem se voltado para a elaboração de consignas políticas gerais, com o evidente intuito de que alguma das instâncias do poder executivo venha a adotá-las. Inegavelmente, tem havido, em nosso fazer político, um predomínio da razão estratégica, conforme a conceituou J. Habermas (1). 
Alguns trabalham com a idéia-força da composição de Blocos vocacionados para a conquista e conservação do poder de estado, visando a conformação de governos de recorte popular e democrático. Outros, mais pragmáticos, contentam-se com o propósito de infiltrar em qualquer governo laivos de reformismo.

Não discuto a correção destas orientações. Questiono, sim, sua suficiência transformadora. Duvido de seu caráter estratégico, de sua capacidade de reordenar a vida em sociedade a partir de uma ótica democrática, libertária e de instauração de uma nova civilização.

Várias experiências polftico-administrativas recentes têm se demonstrado impotentes para alterar o "status-quo", na medida em que não conseguiram favorecer a produção de sujeitos sociais competentes para dar sustentação e prosseguimento a mudanças institucionais. Para isso, seria necessário combinar as disputas mais gerais e pretensamente "mais estratégicas", com uma multiplicidade de microconflitos, valorizando todos os procedimentos para fazer também MICROPOLITICA, conforme a entende F. Guattari (2).

A luta pela transformação das instituições em geral e da saúde em particular, só alcançará sucesso a partir da valorização deste outro plano de luta e implicaria na hipótese de que é possível REVOLUCIONAR O COTIDIANO (e aqui já lá vai uma outra categoria a ser melhor estudada). Em se trabalhar com o pressuposto de que os mecanismos de dominação/exploração - os micropoderes - podem ser questionados e, até mesmo, contrarrestados durante a organização ordinária e comum da vida nas empresas, sindicatos, partidos, instituições ... $E$ que isso pode acontecer mesmo quando ainda não se tenha alterado o esquema mais geral de dominação a nível do estado, da sociedade política e do mundo da produção. 
$\mathrm{Na}$ verdade, significa mais ainda: implica reconhecer que a construção de uma nova hegemonia, de uma nova civilização, depende da criação de inúmeras situações que favoreçam a constituição de atores que neguem a inevitabilidade da permanência do "'status-quo"', que entrevejam possibilidades de alterá-lo e que, principalmente, sintam-se com direito de desejar esta mudança.

Ao contrário da tradição revolucionária que adiava a instauração de relações mais democráticas e justas para depois de algum "grande dia", agora se trataria do contrário: de partir da pressuposição de que a vigência de novas relações dependeria da existência de milhares de sujeitos capazes de autogerirem seu dia-adia, explorando ao máximo as potencialidades de mudança e respeitando os limites, os constrangimentos e as determinações históricos-estruturais de cada contexto.

Em decorrência, poderíamos afirmar que a adesão dos trabalhadores a um novo projeto de sociedade (ou de saúde), depende do reconhecimento de que este novo estilo de vida já é possível hoje. De que o viver cotidiano não precisa obrigatoriamente ser aquele da repetição, da renúncia sistemática à autonomia e ao desejo. Que o trabalho em um Centro de Saúde, Hospital, ou em qualquer outra instituição pública, pode ser um espaço para a realização profissional, para o exercício da criatividade, um lugar onde o sentir-se útil contribua para despertar o sentido de pertinência à coletividade, transcendendo o papel tradicional do trabalho que é o de, quando muito, assegurar a sobrevivência e um determinado nível de consumo. Uma via para transcender a alienação social... uma possibilidade em aberto.

Em cada Instituição se reproduzem, na forma de uma certa síntese, os mecanismos mais gerais de funcionamento da sociedade. As especificidades de cada uma destas cristalizações de poder dizem respeito ao reforço ou ao apagamento de alguma destas características mais gerais, que se repetem nas organizações em 
função da composição de suas forças internas e de suas relações com a sociedade e com o estado. O mesmo acontece com os sujeitos, que conforme sua posição institucional e seu projeto de vida, tendem a reproduzir modelos de praxis dominantes no espaço público. Este espelhamento não é sempre fruto de uma reflexão consciente. Assim, grupos ou indivíduos portadores de um discurso critico da omissão, covardia, ou do proceder egoístico de personalidades ou de agrupamentos dirigentes, no seu agir cotidiano, copiam estes mesmos padrões de comportamento, justificando-os a partir de um pensar pragmático que apresenta a subordinação como única possibilidade de ação conseqüente ou possível.

Deslocar a luz da análise para este mundo do cotidiano pode ser uma estratégia eficaz não só para o processo de construção de consciências crfticas sobre o geral e o particular, mas centralmente ajuda cada homem dominado a superar seus limites, a constituir-se como sujeito e a apostar na construção de outros que como ele acreditem no novo.

O viver sujeitado, conformado à mediocridade, submetido à disciplina de normas burocráticas, à lógica da produtividade pela produtividade, é, ao mesmo tempo, conseqüência da hegemonia capitalista e um dos seus principais meios de reprodução - uma de suas explicações causais.

K. Marx afirmou que um determinado padrão de consumo, um certo estilo de aspiração social, um conjunto de necessidades historicamente constituídas, operam como uma FORÇA MATERIAL (3).

É destas forças materiais subjetivas de que estou tratando. Isto não é idealismo, é uma aplicação possível do materialismo dialético. Toda esta discussão tem como pressuposto a hipótese de que no Brasil já estão dadas as bases materiais para a realização de novos padrões de vida em sociedade e de que os empecilhos 
para tal são políticos, culturais e ideológicos.

Para que estas possibilidades se materializem é necessário reconstruir, destruir, desconstruir, toda uma infinita lógica de micropoderes normalizadores, que produzem o conformismo com a miséria, com a violência, com o autoritarismo, com o modelo vigente de apropriação e distribuição da riqueza.

Haveria que se canalizar a insatisfação, o desejo, e as necessidades sociais das classes dominadas, dos grupos excluídos, dos trabalhadores, das minorias oprimidas, dos profissionais alienados, para um movimento multicêntrico voltado para a ampliação dos espaços de democracia direta, de solidariedade social, de atendimento das aspirações de trabalho e de consumo, enfim, para a constituição de grupos sujeitos de seu destino dadas as possibilidades históricas concretas (4).

Tudo que favorecer a repetição, a conservação da desigualdade, o viver cinza, deve ser colocado em questão. Mesmo quando tivermos a convicção de que só uma parcela destes questionamentos se transformarão em projetos socialmente significativos e viáveis. Esta radicalidade crítica se justificaria tendo em vista que nenhuma instância estaria autorizada, a "a priori", a pré-julgar a viabilidade social de cada possibilidade de mudança. Este filtro não pode ser monopólio nem dos Partidos, nem da Academia, nem da intelectualidade ou das Igrejas e muito menos pode ser um apanágio exclusivo dos Governantes. Dizer o que deve ou não ser discutido e a qual conflito explicitar, não pode ser um privilégio de alguns segmentos, sob pena da infantilização do restante da sociedade.

Repensar não só o poder de estado, mas o argumento de autoridade, o poder excludente do império absoluto da lógica da rentabilidade máxima - máquina de produzir os párias do progresso. Questionar todas as absolutizações autoreferentes, a desvalorização automática do outro-diferente. Valorizar as 
possibilidades de composição de diferenças sempre que isto resulte no enriquecimento dos projetos de reconstrução da sociabilidade democrática. Admitir o conflito, seus mecanismos cotidianos de explicitação, articulá-los à disputa pela hegemonia, pela criação de uma certa habilidade dirigente, mas criar mecanismos que dificultem o predomínio das formas mais primitivas e destruidoras de sublimação - as realizações pessoais que impliquem na exploração do outro, na sua redução a um objeto descartável.

E que os Governos, ou Partidos, que forem mais espelho e, ao mesmo tempo, agentes ativos da multiplicação destes microprocessos, e que, além do mais, consigam articulá-los em síntese abertas, sejam os Representantes-Príncipes do Príncipe Moderno que é o homem, as classes sociais, capazes da ousadia de almejar a condição de sujeito da história. Príncipe contemporâneo.

Imagino que assim se deveriam plasmar os Governos e Partidos Revolucionários deste nosso tempo. Em que - usando e adaptando algumas metáforas de Gramsci - da guerra de Movimento (quebra abrupta do poder de estado), deveríamos passar à guerra de posição (processo de acúmulo de forças concomitante e através de disputas pelo poder em cada instância da sociedade civil e do Estado), e ainda à guerra de guerrilhas (em analogia ao modelo dos embates guerreiros e aqui aplicado como uma metáfora à disputa política, intelectual e ideológica nas sociedades modernas). Ou seja, advoga-se uma forma complementar de luta onde o combate à dominação se daria a partir de todos os planos e em todos os tempos - micro e macro-reconstrução social, econômica e psíquica de indivíduos e coletividades e instituições. Um pouco elaborando uma síntese dos conceitos de Revolução Molecular de Guattari e de luta por uma nova civilização em Gramsci (5).

Por exemplo, ousar pensar a democratização dos meios de comunicação, não só propondo sua estatização ou a criação de micro-rádios piratas, 
mas ousar pensar nos grandes complexos de comunicação como Fundações Públicas cogeridas pelos trabalhadores de comunicação e por representantes da sociedade civil.

Ousar pensar um novo hospital já possivel, uma nova Saúde Pública, novos processos de trabalho em saúde estimuladores e propiciadores do desenvolvimento de novas relações com a doença, com os cidadãos, com a tecnologia - velha tecnologia.

Ora, julgo que nas instituições de saúde há possibilidades singulares para o desenvolvimento deste tipo de processo transformador.

Para tal creio que teríamos que desencadear um movimento em três dimensões, de maneira que um potencializasse e, ao mesmo tempo, se apoiasse nas transformações resultantes dos outros dois. $O$ império da velha dialética.

Identifico a possibilidade de se instaurar uma série de alterações dos mecanismos de gestão e dos processos de trabalho em saúde (alterações estruturais) que atendessem às necessidades de saúde da população e às possibilidades de realização profissional e pessoal dos trabalhadores de saúde (6). Este seria um dos planos.

A questão que permanece é com que instrumentos operar estas modificações. Na realidade, não se trata apenas de imaginar novos projetos técnoassistenciais, mas de identificar QUEM os construirá e quem os implementará enquanto um movimento de luta política, de reforma "intelectual e moral". Aí, entram o segundo e terceiro níveis de construção do novo: no caso, articular a "vontade polftica e deliberada de agir e a capacidade reflexiva" (7) de dois atores sociais centrais ao movimento de reforma sanitária: os trabalhadores de saúde e todos os setores da sociedade que dependem de um sistema público de saúde para assegurar 
a manutenção da sua vida. Propor modificações estruturais que não só atendam às necessidades destes dois segmentos, como também sejam propiciadoras da sua constituição como sujeitos coletivos. Estruturas, instituições, que estimulem a autonomia e a capacidade de direção, superando seu tradicional papel de produzir alienação. E realizando estes três movimentos ao mesmo tempo, a partir de possibilidades já existentes no contexto dos serviços públicos de saúde e da sociedade brasileira.

Neste artigo, não abordarei exaustivamente estas três dimensões que imagino estratégicas para a reforma da saúde. Desenharei apenas algumas vias pelas quais poderíamos abordá-las.

Tomemos os trabalhadores de saúde. Vários trabalhos têm analisado com ceticismo a possibilidade deles virem a jogar um papel impulsionador da reforma. Apontam o marcado corporativismo de suas demandas polfticas e sindicais e identificam a existência de inúmeros pontos de tensão entre os seus interesses e os da coletividade. Para estes autores os profissionais estariam estrutural e subjetivamente presos ao seu corporativismo ou a um processo de burocratização. Condenados à alienação eterna, ao gueto da insensibilidade social que os impediria de compor representações para além de seus interesses imediatos.

Em certa medida, o meu livro "Os Médicos e a Política de Saúde" também vê os médicos de tal forma enredados em uma trama infra-estrutural que parece difícil imaginá-los em outra posição que não a de ideólogos do neoliberalismo.

Por outro lado, é inegável que a estas dificuldades se agregariam ainda uma certa apatia e uma indiferença frente a degradação das instituições de saúde, fatos empírica e historicamente constatáveis e que não são exclusivos deste segmento social. 
Ou seja, compõe-se um quadro de aparência tenebrosa. Justificando-se a tendência atual de se depositar as esperanças de mudança em outras instâncias: em governos progressistas, nos usuários. No entanto, como G. Berlinguer colocou, nunca haverá reforma sanitária contra os trabalhadores de saúde. Dizendo de outra forma: não é viável, no Brasil, uma estratégia reformista que aposte principalmente no controle, no enquadramento dos profissionais de saúde e não em sua incorporação ao processo como sujeitos da reforma.

Não o é por que aqui, ao contrário do que aconteceu em alguns outros países, não houve uma dinâmica revolucionária que tornasse possivel a implantação de Sistemas Públicos a partir de outros apoios sociais (Estado, Partido no governo). Mesmo nestes casos, contudo, não houve uma radical alteração das práticas sanitárias, já que transformações neste nível não se efetivam sem o concurso ativo dos trabalhadores de saúde.

No entanto, faz-se necessário uma profunda revisão sobre o papel que os mal-denominados "recursos humanos" jogarão no processo de reforma sanitária. $\mathrm{Na}$ realidade, tem sido pouco estudado o que se passa realmente com os trabalhadores de saúde.

Em geral, utilizam-se metodologias restritas à sociologia das profissões, à análise de discurso, quase nunca sendo abordada a principal característica deste objeto de estudo que 0 de serem sujeitos, com todas as conseqüências metodológicas que este conceito impõe.

Observando os trabalhadores de saúde da área pública constatamos que eles estão frustrados, descontentes, trabalhando pela sobrevivência e para garantir um certo nivel de consumo. Há uma marcada e especial alienação destes profissionais em relação ao seu objeto de trabalho (ligação débil com a doença ou 
saúde do outro), ao seus meios de trabalho (uma separação progressiva entre os que executam ações e os que dirigem as instituições) e também em referência à equipe de saúde (há trabalho em grupo mas não há identidade do trabalhador coletivo)(8).

Ora, neste contexto, para a maioria, lavra um descontentamento com o "status quo", uma vez que este não favorece a realização profissional e pessoal. Ou seja, há bases concretas para a construção de um projeto sanitário que aponte para a superação deste quadro e atenda aos interesses dos usuários do sistema.

A realização do homem moderno depende de um complexo de desejos, interesses e necessidades, resultantes de um dado processo histórico, da posição social e da capacidade de luta e de formulação consciente de cada sujeito. Este complexo tem sempre uma expressão individual, que, em alguma medida, é também referente às possibilidades sociais que conformam limites para os desejos e necessidades.

Castoriadis entende que o processo de constituição de sujeitos humanos autônomos vincula-se às possibilidades histórico-sociais do indivíduo pulsional substituir o prazer do objeto pelo prazer da representação (9). Ou seja, a socialização dependeria da capacidade de sublimação dos sujeitos, e que o ato de sublimar seria o mecanismo por meio do qual as necessidades históricas (dimensão do coletivo) encarnam-se, segundo inúmeros caminhos mas segundo alguns caminhos histórica e socialmente determinados, em cada e em todos os indivíduos.

No entanto, eu considero que a capacidade de sublimar não assegura automaticamente a superação do egocentrismo, do preconceito contra o outro, do imediatismo pulsional e muito menos da expressão polftica deste tipo de proceder, como o são os casos do corporativismo e de todos os individualismos. Entendo que a obtenção do prazer por meio da representação pode ocorrer em três planos, e que 
o atendimento dos desejos e interesses segundo cada um destes planos têm conseqüências sociais e políticas bastante distintas.

O primeiro destes planos - o mais próximo do modelo instintivo da satisfação do desejo sexual e, portanto, neste sentido, mais primitivo - opera através de uma defesa imediatista e agressiva do indivíduo em todas suas relações sociais. $\mathrm{Na}$ dimensão sexual busca-se a satisfação imediata sem considerações sobre o fato de que o objeto do desejo, no caso, é um sujeito dotado de sensibilidades e de desejos - não há espaço para o amor romântico entre dois indivíduos-sujeitos. 0 trabalho objetiva dar acesso ao consumo imediato. As relações sociais estão marcadas pelo receio e agressividade automática contra o outro, sempre um rival em potencial.

Seria ocioso apontar que este padrão de sociabilidade, de subjetividade, é predominante entre aquelas camadas sociais excluídas das possibilidades médias de fruição social do prazer em uma dada sociedade. Refiro-me aos meninos de rua do Brasil, aos jovens cronicamente desempregados, entre outros segmentos. Vale acrescentar que este modelo de construção de subjetividade não é exclusivo das pessoas submetidas a estas condições de vida. Pode também resultar de uma certa história familiar, o que indica que a reprodução deste homem-lobo recorta todas as classes sociais, mas que, certamente, tem condições mais favoráveis de reprodução entre os socialmente excluídos e entre aqueles que não experimentaram quase que nenhum tipo de experiência institucional, senão aquelas das instituições totais. A manutenção de modos de andar a vida que produzem este tipo primitivo de sublimação representa uma permanente ameaça para 0 progresso e para democracia. É a base sobre a qual se assentam as várias formas de facistização do cotidiano, da política e da cultura.

A segunda forma genérica de articular necessidades e desejos a certos 
padrões de representação e de agir deliberado é aquela que mais se aproxima do espírito do capitalismo. Neste campo há uma maior presença do princípio de realidade e a obtenção imediata do prazer pode ser adiada em função do sentimento de segurança. Segurança que se expressa centralmente via acumulação. Acumulação de poder, de capital, de vitórias esportivas ou de conquistas sexuais, acumulação de possibilidades garantidas da efetivação do ato sexual - o casamento como contrato em que a mulher estaria teórica e legalmente à disposição. Neste caso, a impossibilidade do trabalho prazeroso é compensada por sua função de assegurar riquezas, promessa de um consumo futuro. Mesmo o objeto de consumo muda de sentido, não é mais necessariamente consumido, se consome para a acumulação: livros que não se lê, discos que não se ouve, roupas que não se usa, objetos que se acumulam. Os colecionadores.

Indubitavelmente, o predomínio deste tipo de subjetividade tem criado um certo estilo de civilização, onde os sujeitos têm, obrigatoriamente, que levar em conta o interesse dos outros. O outro continua sendo um antagonista em potencial, mas é um antagonista que nos diz respeito, com o qual temos que negociar, ou a quem se deve submeter. É o mundo da produtividade, da competição como principal aguilhão do agir em sociedade, é um mundo que oferece milhões de objetos ou de relações nas quais poderíamos investir nosso prazer de representação. Mas é o mundo da busca compulsiva da segurança, e o que seria a segurança absoluta senão o congelamento do presente, o fim da história, a regulação e normalização dos desejos, um mundo que o futuro já está todo no presente. Enfim, é mundo forte, mas impossivel, apesar de toda sua concretude, um mundo do qual se escapa consciente ou inconscientemente a todos os momentos: por ressentimento autocomplacente se escapa para os primeiros níveis de sublimação; ou se escapa por esperança para um terceiro projeto de vida em sociedade.

O primeiro destes planos tinha como eixo integrador o agir voltado para 
o imediatismo e urgência da necessidade de sobreviver a qualquer custo - inclusive, ao da destruição do outro. O segundo, funda-se na segurança e restaria um terceiro modo de socialização capaz de compatibilizar o atendimento do interesse individual com uma certa dose de segurança, mas superando os aspectos exclusivistas destas duas primeiras modalidades, na medida em que parte de idéia força de que o outro das relações individuais ou sociais é sempre um sujeito também desejante, também portador de uma certa legitimidade ou de uma possibilidade de legitimidade desde que alteradas determinadas relações de poder pessoal, institucional, politico ou econômico.

Ou seja, neste terceiro plano de socialização os sujeitos partem da realidade do conflito de interesses, mas procuram resolvê-lo a partir da articulação de novas relações que tornem regra o trabalho criativo, que instituam projetos fundados na solidariedade e na destruição/superação dos mecanismos autoritários e subordinantes dos planos anteriores e dos blocos de poder articulados para preservá-los. No plano do afeto apostar-se-ia que dois sujeitos autônomos podem realizar seus desejos combinando suas vontades a partir de um processo cotidiano e voluntário de entendimento. O trabalho seria sempre um espaço para assegurar a sobrevivência, o consumo, mas também não se renunciaria mais às suas potencialidades prazerosas, ligadas à sua dimensão criativa e, no caso da saúde, de realização da solidariedade.

A generalização deste terceiro padrão de subjetividade não depende apenas da vontade de militantes ou de intelectuais. E nem poderíamos esperar que uma impossível e indefensável psicanalização de massa a instituísse, não haveria "settings adequados" em número suficiente para tal e tampouco os psicanalistas propõe-se a realizar tal empreitada. De fato, a sua universalização dependeria da construção de movimentos, de espaços institucionais e, até mesmo, de leis, que estejam de acordo, que produzam ativamente este padrão de socialização. Não se 
trata de mais uma afirmação paradoxal, mas da velha dialética cobrando sua incontornável relação com a realidade social.

Portanto, na saúde, é possível a superação/incorporação do corporativismo e do descontentamento hoje vigentes entre a maioria dos profissionais, transformando-os em capacidade dirigente. Gramsci já havia afirmado, há muito tempo, que todo homem é um filósofo e um dirigente em potencial, um criador e há condições materiais e subjetivas para o florescimento deste estilo de reformas econômicas, intelectuais e morais.

É na "gestão" do cotidiano que se constrói esta ou aquela subjetividade, sujeitos autônomos ou sujeitados. Na saúde, a revolução do cotidiano passa pela reforma dos modos de fazer a clínica, a saúde pública, pelos modos de gerir e de distribuir o poder nas instituições, pela delegação/instituição de novas cotas de responsabilidade e de autonomia. Passa também pela redefinição dos critérios de cura, do papel dos serviços de saúde - colocá-los à serviço da reprodução da vida. Envolve novas formas de ACOLHIMENTO do sujeito individual ou coletivo que necessita de atenção especffica, pressupõe a personalização das relações equipe de saúde com até agora objeto da assistência, enfim... Mas, toda esta discussão já abre as portas para novos artigos, outras abordagens... 


\section{NOTAS BIBLIOGRÁFICAS}

1. Habermas, Jurgen - Consciência Moral e Agir Comunicativo - Rio de Janeiro, Tempo Brasileiro, 1989.

2. Guattari, Felix e Rolnik, Suely - MicroPolítica - Cartografia do Desejo - Rio de Janeiro, Vozes, 1986.

3. Marx, Karl - Elementos Fundamentales para la Crítica de la Economia Política, Vol.1 - Buenos Aires, Siglo XXI, 1971.

4. O conceito de grupos sujeitados e sujeitos foi utilizado por Guattari em uma certa fase de sua obra e aparece em Revolução Molecular: pulsaçōes Políticas do Desejo - São Paulo, Brasiliense, $2^{\mathfrak{a}}$ edição, 1985.

5. Gramsci, Antonio - "Paso de la guerra de movimiento (y del ataque frontal) a la guerra de posición tambien en el campo político", In: Antologia - México, Siglo XXI, 3a edición, 1977, pág. 192. conceito de Revolução Molecular é de Guattari e aparece na obra citado no item 4.

6. A análise mais sistemática das possibilidades de desenvolvimento de reforma estrutural dos sistemas públicos e das práticas em saúde aparece em meu livro: Reforma da Reforma: Repensando a Saúde São Paulo, Hucitec, 1992, no capítulo N.

7. Castoriadis, Cornelius - "O Estado do Sujeito Hoje", In: O Mundo Fragmentado - Encruzilhadas do Labirinto III - Rio de Janeiro, Paz e Terra, 1992.

8. O estudo da alienação no trabalho em saúde aparece em um artigo de minha autoria: "A Gestão enquanto um componente estratégico para a implantação de um serviço público de saúde", In: A Saúde Pública e a Defesa da Vida - São Paulo, Hucitec, 1991.

9. Catoriadis, Cornelius - idem ao item 7. 